\title{
Study on the Mechanism of Upgrading the Quality of Personnel Training in Universities of Finance and Economics
}

\author{
Ma Hongxing, Guan Yamei \\ Department of Accounting, Nanjing University of Finance and Economics, Nanjing 210023, China \\ Mahx215@126.com, guanyamei@sina.com
}

\begin{abstract}
The "Big Finance" educational idea was proposed to adapt to the new educational environment and educational background of the new period. Its starting point was to broader perspectives. In this essay, analysis the problems of active quality guarantee system, based on the reference of American's education system, we attempts to do a new study on building a high quality of talents training system for the finance and economics colleges from the perspective of "Big Finance".
\end{abstract}

Index Terms - Big Finance, Quality guarantee system, Personnel training

\section{Introduction}

The educational idea of "Big Finance" was proposed by the Party committee secretary of Nanjing University of Finances and Economics Chen Zhanglong in accepting the interview by "Guangming Daily" reporters. He said, the socalled "Big Finance" refers to the integration of multiple disciplines, making the economics and management students also have the political quality and international vision at the same time and putting the economic management courses into every profession, letting the students major in Journalism, English and other non business majors marked with deep financial brand.

The "Big Finance" educational idea was proposed to adapt to the new educational environment and educational background of the new period. Its starting point was to broader perspectives. By training students who are more responsive to the social needs of the application type and compound talents under the "Big Finance" perspective, to build a broader pattern of social services and collaborative innovation of scientific research system. The personnel training system from the perspective of "Big Finance" includes the construction of a high level of teachers, a high level of social service system, a high level of the quality of talents and so on. The ultimate goal is to meet the strategic needs of the national economic transition, to meet the social demand for a strong talent, escaping from the professional bondage and training the application type and compound talents leading the future.

Based on the "Big Finance" perspective, the quality of talents training system of the current finance and economics colleges has become increasingly unable to meet the strategic needs of the national economic transition. Therefore, this paper attempts to do a new study on building a high quality of talents training system for the finance and economics colleges from the perspective of "Big Finance".

\section{The Running Mode and Problems Exist in Current Higher Education Quality Assurance System.}

\subsection{The running mode of current higher education quality assurance system.}

The existing quality assurance system of higher education is mainly based on the undergraduate teaching level evaluation work, which usually administered by the Ministry of Education. Its assessment policy is: through the evaluation to promote the construction, reforms and management, combining the evaluation and construction, focusing on the construction. The main content of the assessment are: school of thought, the construction of teachers' team, conditions and utilization of the teaching, building and reforms of the teaching, teaching management and construction of the style of study. Its running mode is composed of the following three stages: self assessment stage, expert on-site inspection stage, rectification stage.

\subsection{The problems exist in current higher education quality assurance system.}

From the results of the first round of university evaluation in 2008, we can see that every college paid much attention to the evaluation results. The evaluation results have a certain influence and have a certain role in promoting the quality of teaching and the improvement of education. But, inevitably, there are some problems exist in the current higher education quality assessment system:

\subsubsection{The administrative color of the evaluation of the quality of higher education is too thick.}

China's "Higher Education Act" provides that the colleges' school level and teaching quality should accept the supervision and evaluation from the educational administrative departments and its organization. Therefore, the evaluation of College Teaching in our country is carried out by the national Ministry of education, which is a single administrative assessment with mandatory, lacking the participation of civil education assessment agencies and well-known media. Thus, assessment of the social influence is not broad enough.

In this evaluation mechanism, the government has a condescending attitude, control of the whole operation and all aspects of the evaluation of higher education. Whether the evaluation content and evaluation procedures are fully infiltrated the government will, which makes the university as 
a school subject will not be reflected. University cannot exert its autonomy enough in the quality assurance system, had to meet the government's quality assessment passively and can not actively carry out in accordance with the higher education as the main body in demand as the guidance within the quality of the operating mechanism.

\subsubsection{Single standard of higher education quality assessment}

The standard of China's higher education quality assurance system is single. Academic achievement is not only a single standard used by the current higher education quality assurance system, but also a main goal of colleges and universities of all types and at all levels to pursue to improve their teaching quality. In order to academic and academic. This evaluation standard can not really reflect the objectivity and authenticity of the education quality. Because school forms and talent demand is diversification. To measure every school with a single academic standard will generate a passive situation to deal with the evaluation. Some colleges' characteristic cannot be reflected and attached great importance to, or may even be threatened. It is hard to ensure the effect of quality assurance.

\subsubsection{Higher education's quality evaluation conclusions lack of credibility}

At present, the higher education's quality assessment is mainly to evaluate the teaching attitude, teaching content, teaching methods and teaching effect. The scope of the assessment is narrow. Meanwhile, it ignores the students which as one of the main factors of education and ignores the students' participation in school teaching quality evaluation. The main body of the higher education quality assurance system is students. The lack of the participation of the student body cannot guarantee the teaching quality from the source. Single appraisal standard leads to a drop in reliability and validity of the evaluation. The assessment conclusions are over-modeled, lack of check and review and less point out the shortcomings and the insufficiency in reality, which resulting in the evaluation conclusions lack of credibility.

\section{American Higher Education Quality Assurance Model and Comparison with China}

\subsection{American higher education quality assurance model}

The United States Constitution provides that local and state governments at all levels are responsible for their own higher education. It means that the government would not directly intervene in the daily teaching activities and universities have full autonomy for autonomy. The government only indirectly, by way of fiscal budget, funding and other manners affects the higher education. Therefore, the quality assessment of colleges and universities in the United States is initiated by the specialized agencies and non-governmental organizations at all levels. It is a folk-oriented quality assurance assessment model.

\subsubsection{The academic ranking of colleges and universities}

In the United States, the academic ranking of colleges and universities is mainly organized by the news media, such as
"Business Week", "U.S. News And World Report" etc. With the help of a specific index system, general according to the professional or school ranking and regularly issued list. The list has a certain reference value and plays a guiding role for students and parents on the choice of schools.

\subsubsection{The authentication of higher education appraisal committee.}

American higher education appraisal committee has the high authority, and is the highest education certification for American folk organization. To get social recognition, colleges' and universities' certification bodies in the United States must be recognized by the organization. There are two main responsibilities: to review and verify the qualification and quality of the national professional certification institutions and universities recognized institution; review qualification and quality of the regional institutions.

\subsubsection{The evaluation of teaching quality in colleges and universities}

The evaluation of teaching quality of colleges and universities is the internal self -assessment. The main content of the self assessment is: level of teaching, scientific research and scientific research assessment, student assessment and professional assessment. Compared with external appraisal, internal appraisal is more directly conducive with the resource allocation, the school planning and new school professional settings and so on.

\subsection{The comparison of higher education quality assurance model}

Our country's higher education quality assurance mode is government-leading, and American higher education quality assurance model takes folk evaluation as the leading factor. There are big difference between them in such aspects as politics, economy and culture.

\subsubsection{The difference in political environment}

American constitution does not give the government the right to intervene higher education, even the states have no right to intervene the internal affairs of the university. except through government budget to implement simple impact. Therefore, colleges and universities have great autonomy, which gives big development space for the maintenance of education feature and teaching ideas. As a contrast, our country's higher education law rules that ministry of education has comprehensive leadership and evaluation of higher education. Quality assurance system is completely led by government, and colleges and universities lose status as a host, not to mention the spontaneous adjustment and constraints of market.

\subsubsection{The difference in the economic environment}

America's economic develops faster than other countries, and the market operation system of higher education is more mature. American university has less reliance on the government's money and most of them operates independently, takes active participate in the competition of higher education market, and has strong adjustment ability to the change of 
economic environment. As a contrast, Chinese government still dominates the education quality assurance mechanism and even in the monopoly place. When Chinese colleges and universities face the rapid economic development, their adjusting ability and adaptability are lagging, which makes the quality of higher education not match economic development.

\subsubsection{The difference in the cultural environment}

The difference of higher education quality, determines a country's selection of higher education training target and the level of education quality. The idea of "Humanism" has been universally accepted, this theory underlines that the process of higher education is that of students to have continuous development and improvement. The feature of "Humanism" in the United States is very obvious-the higher education system pay special attention to ensure quality of students' development and it develops and improves the students' intelligence, insight, personality and ability to participate in social aspects and so on. China's higher education focus on social values for a long period of time, it pays less attention on individual value and academic value.

\subsection{Reference of American Higher Education Quality Assurance System}

\subsubsection{The reference to the concept}

Most of the financial universities in our country are comprehensive ones which are mainly about economic management disciplines, supported by economics, management, law, engineering, literature, science and other multi-disciplinary. In the process of running university, through multidisciplinary intersection, students majoring in economy management also should have political literacy and international vision. At the same time, students who don't major in fiance and economics are deeply influenced by finance and economics through economy management classes deeply rooted in every major. Upholding this concept, we should insist on diversified personnel training.

\subsubsection{The reference of method}

Since university internal evaluation is the premise and foundation of external evaluations. In finance, therefore, the teaching quality of institutions of higher learning in, we should plant "big finance and economics" evaluation indicators and evaluation factors into the process of self-evaluation, and implant more non-professional curriculum into economic management courses, to further embody the feature of "big finance and economics". In addition, we should pay attention to the combination of school self-evaluation and external evaluations. Therefore, the smooth implementation of quality assurance system of "big finance and economics" must combine internal evaluation with external evaluation.

\section{Talent Cultivation Quality Improvement Mechanism based on the Concept of the "Big Finance"}

\subsection{The concept of talent cultivation quality improvement mechanism}

At present, higher education is gradually internationalized. Both the declaration of Tokyo, which is passed on the international quality assurance conference on higher education held in July 2001, and the international higher education quality assurance association (INQAAHE) which is formed on the world university presidents meeting , make us realize that the world are trying to establish a global higher education quality evaluation standard, and actively build mutual recognition between countries in the world of international standard system of qualification certificate, diploma and degree. There is no doubt that the internationalization of higher education quality assurance mechanism is the inevitable choice and development trend of China's higher education. However, the China's higher education has just entered the popularization stage, and big gap in talent training quality compared with the developed countries. We can improve our talent training mechanism through positive support, guide and encouragement of innovation in colleges and universities.

\subsection{The basis of the mechanism of promoting talent training quality}

Teaching quality monitoring system is the basis of the mechanism of promoting talent training quality. It is consist of program control, tracking control, adaptive control and optimal control. It can accurately and timely collect first-hand information of teaching quality and form a comprehensive information communication and feedback mechanism of control the teaching quality to build perfect teaching quality monitoring system .

To build teaching quality monitoring system of colleges and universities, we should blend big finance and economics in it and make it embody big finance and economics concept in every link of teaching quality monitoring, We should further the "big business" concept throughout the teaching quality monitoring network.

\subsection{Guarantee of the promotion talent training quality mechanism}

The construction of he promotion talent training quality mode the of business colleges and universities under the horizon of the "big finance" is not only influenced by the government macroeconomic regulation and control, but also by social demand and recognition for talents and. Government takes the role of macroeconomic regulation and control in higher education guarantee system, mainly through legislation, 
administrative guidance, economic means and evaluation. Society takes the charge of adjustment, mainly through the guidance of social economy, the social supervision, social intermediary organizations. Therefore, we need to put the concept of the promotion talent training quality mechanism under the horizon of "big finance" into the social environment, to accept the inspection of the society.

\section{Acknowledgment}

This paper Founded by Jiangsu philosophy and society science fund (12DJC006); Jiangsu education science "the twelfth five year" project fund (B-a/2013/01/012); Education research project of Nanjing university of finance and economics (2013003)

\section{References}

[1] Chen Zhigang. The development trend of our country's personnel training. Education Observyiting, 2003(21):29-35.

[2] Song Chang, Wu Shaohua. The review and look ahead of our country's education management. Education Research, 2004 (2):49-53. 